\title{
G+ COMMUNITY: MEASURING TEACHERS' READINESS AND ACCEPTANCE
}

\author{
Muhamad Hazrul Bin Haris Fadzilah1 \\ Mohd Faisal Farish Bin Ishak ${ }^{2}$ \\ Rashidah Binti Rahamat ${ }^{3}$ \\ Abdul Ghani Abu4 \\ Ministry of Education, Malaysia \\ (1hazrul.haris@eltc.edu.my, 2faisalfarish@eltc.edu.my, \\ 3rashidah.rahamat@eltc.edu.my, ${ }^{4}$ a.gani@fbk.upsi.edu.my)
}

\begin{abstract}
The purpose of this paper is to explore teachers' acceptance and readiness in using the cloud-based community as a platform for professional collaboration related to their teaching and learning. Familiarity with certain social networking platforms has made the preferable collaboration among teachers only limited to using Facebook, WhatsApp or Telegram. However, with time and space constraints in schools, some of the sharing sessions could not be done effectively most of the time. The study focuses on teachers' acceptance and readiness of having their community in the cloud when they were introduced to the platform during a Continuous Professional Development (CPD) course. A total number of 61 teachers used Google Community named as 'Contemporary Children's Literature (CCL) 2016' as a platform for their Professional Learning Community (PLC) during the course. Descriptive analysis was done using Google Sheets and the findings show that these teachers are receptive towards Google Community in terms of its engagement level, usefulness as well as ease of use. The introduction to Google Community has created a new pathway for their collaboration especially for teaching and learning purposes. In a nutshell, their acceptance towards the cloud-based community indicates that, given the right training channel, teachers are positive and opened to utilising and integrating the cloud-based technology in their current teaching practice.
\end{abstract}

Keywords: Cloud-based community, Google Community, PLC, collaboration

\section{INTRODUCTION}

Familiarity with certain social networking platforms has made the preferable collaboration among teachers only limited to using Facebook, WhatsApp or Telegram. However, with time and space constraints in schools, some of the sharing sessions could not be done effectively most of the time. Hung 


\section{EduLite}

Journal of English Education, Literature, and Culture

Volume 2, Number 2, August 2017

and Khine (2006) mention in his critical review that it is vital and in fact appropriate for educators to engage learning with the emerging technologies because they view today's era is where the notion “...engagement with learning is likely to mean engagement with technology". Ally (2009) highlighted the use of mobile technologies in the teaching and learning to enhance teaching and learning process, and how the technologies available can be explored further for teaching and learning. As we can see, technology is the focal medium. Interestingly, the directions of using static and mobile technologies for teaching and learning are slightly changing. Obviously, the popularity of social media exploration for teaching and learning is now transpiring researchers to consider the possibilities. According to Joosten (2012), how the social media has changed educator's professional communication, pedagogy, perceptions and management has become the main highlights in most educational platform discussions such as conferences, seminars or workshops. He further points out the issue of the success as well as the effectiveness of the implementations will only be dealt properly if educators know the reasons for using the technology.

This study focuses on teachers' readiness and acceptance of having their community in the cloud when they were introduced to the platform during a Continuous Professional Development (CPD) course. Therefore, this paper aims to explore teachers' readiness as well as their acceptance towards cloud community created through Google+ Community application. The objectives of this paper are to seek answers to the following questions: 1) How does the teachers' readiness towards G+ Community affect their actual use of the application? 2) How does the teachers' acceptance towards cloud community affect their actual use of the application?

\section{Related Review of Literature}

This section shall focus on the related literature involved. The selected reviews towards the subject would be related to the definitions as well as the underlying concepts. 
Hazrul, Farish, Rashidah, $\mathbf{A b u}, G+$ Community: Measuring Teacher's Readiness...

\section{Social Media}

The definition for this terminology was utilised to "crowdsource" (Joosten, 2012) based on the "distinctive characteristics of social media" (Joosten, 2012). Joosten (2012, p. 6) defines it as “...a virtual place where people share; everybody and anybody can share anything anywhere anytime". This scholar also highlights that social media is social networking sites; he cited the definition for this term based on Boyd's and Ellison's (2007) as

"...web-based services that allow individuals to: 1 . construct a
public or semi-public within a bounded system; 2 . articulate a list
of other users with whom they share a connection; and 3 . view and
traverse their list of connections and those made by others within
the system".

Joosten (2012, p. 8)

Technology Acceptance Model

One of the common models being referred to by researchers in exploring the user's acceptance towards a newly introduced technology, would be the Technology Acceptance Model or known as TAM by Davis (1985). It is in fact widely known by scholars who were and are going to investigate the acceptance towards the use of new technology. Venkatesh $\&$ Davis (2000, p. 187), claim that, TAM is "...a robust, powerful, and parsimonious model for predicting user acceptance". This is also mentioned by Chuttur $(2009$, p.1) who points out that, TAM “...has been the only one which has captured the most attention of the Information Systems community". According to Chuttur (2009), the proposed model by Davis in 1985 has gone through a few refinement processes, but the basic measure applied is based on two fundamental factors: the use and ease of use of the technology. The understanding of the model is easily understood by looking at Figure 1. User's intention to use any introduced system is influenced greatly by the at attitudinal factor and this attitude is further influenced by two other factors: the perceived usefulness and perceived ease of use. User's 


\section{Edulite}

Journal of English Education, Literature, and Culture

motivation whether to accept or reject any system, is easily measured through this model.

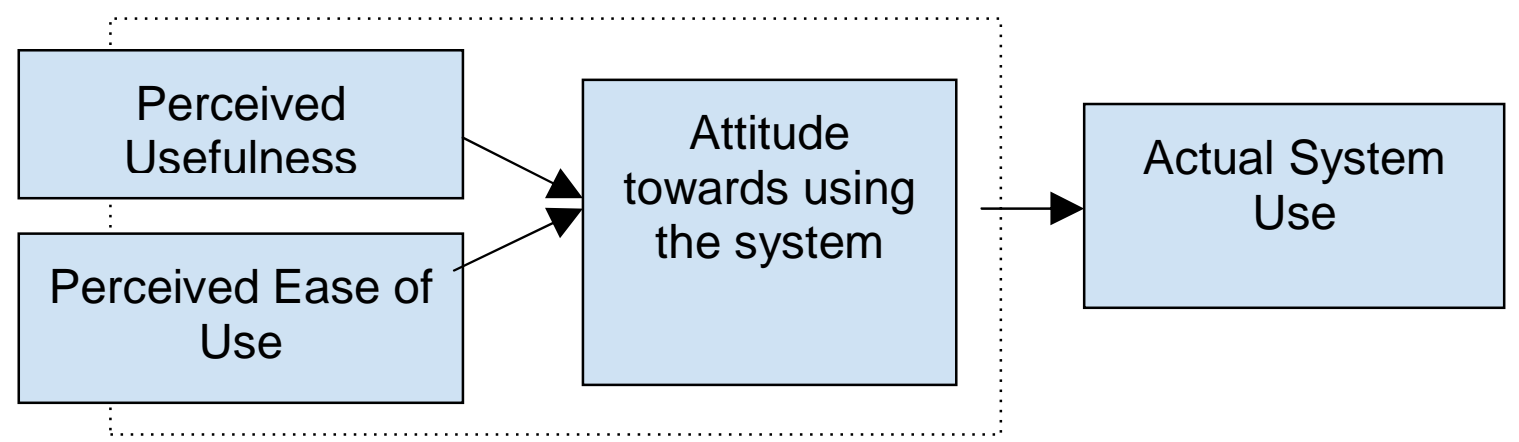

Figure 1: The Original Technology Acceptance Model (Chuttur, 2009)

Readiness

Readiness is one of the important variables being focused in this study and the term is defined as "The state or quality of being ready; preparation; promptness; aptitude; willingness. Prepared for what one is about to do or experience; equipped or supplied with what is needed for some act or event; prepared for immediate movement or action" (Turnbull et. al., 2010). As pointed by Schreurs, Ehler and Moreau (2008, p. 3), readiness also takes account of a person's capability to adapt to "...technological challenges, collaborative training and synchronous as well as asynchronous self-paced training”.

Technology Readiness Index (TRI)

Based on the literature found, readiness towards technology is one factor which can be researched on and in fact, it can be done as self-evaluation. Parasuraman (2000) defines this terminology as

“...people's propensity to embrace and use new technology for accomplishing goals in home life and at work...can be viewed as an overall state of the mind resulting from a gestalt of mental enablers and inhibitors that collectively determine a person's predisposition to use new technology"

Parasuraman (2000, p. 308) 
Hazrul, Farish, Rashidah, $\mathbf{A b u}, G+$ Community: Measuring Teacher's Readiness...

This scholar further explains that, the use of technology may prompt positive and negative feelings among users; these two feelings can be laid out what he called as "the technology-beliefs continuum" which is anchored by strongly positive or strongly negative feelings. Parasuraman (2000) has categorized the technology readiness index level under 4 main categories which are: Optimism, Innovativeness, Discomfort and Insecurity.

In another review, technology readiness level is mostly used by the Department of Defense (specifically NASA) in 1974 and revised in 1990 with nine levels of readiness (Banke, 2010). Based on this, NASA has listed out the nine levels of technology readiness as in the following: Level 1: Basic principles observed and reported; Level 2: Technology concept application formulated; Level 3: Analytical and experimental proof of concept; Level 4: technology validated in lab; Level 5: Technology validated in relevant environment; Level 6: technology demonstrated in a relevant environment; Level 7: System prototype demonstration in an operational environment; Level 8: Actual system completed and qualified, and Level 9: Actual system proven through successful operations.

\section{DISCUSSION}

This small-scale study deployed a mixed-method approach in collecting and analysing the data. The following sub-headings shall detail out the related aspects of the methodology.

\section{Participants}

The participants involved in this research were the English Language teachers teaching in the primary schools. They attended a course known as Contemporary Children's Literature course held in the institution for 3 days in different 3 cohorts. The total numbers of participants were 95 teachers who came from different states based on their zones. The demographic analysis of the participants also showed these groups of teachers have different teaching 


\section{EduLite}

Journal of English Education, Literature, and Culture

Volume 2, Number 2, August 2017

experience based on the year they were born as well as from the observations during the course. The following table shows the summary of the participants.

Table 2: The Participants attending the course

\begin{tabular}{|c|c|c|c|c|c|}
\hline \multirow[t]{2}{*}{ Cohort } & \multirow[t]{2}{*}{ Date } & \multirow{2}{*}{$\begin{array}{l}\text { Total No. of } \\
\text { Participants }\end{array}$} & \multicolumn{2}{|c|}{ Gender } & \multirow[t]{2}{*}{ Zone } \\
\hline & & & Male & Female & \\
\hline 1 & $\begin{array}{l}\text { 5.4.2016- } \\
7.4 .2016\end{array}$ & 46 & 4 & 42 & $\begin{array}{c}\text { Central, North, } \\
\text { South \& East Coast }\end{array}$ \\
\hline 2 & $\begin{array}{l}\text { 9.5.2016- } \\
13.5 .2016\end{array}$ & 11 & 3 & 8 & Central \\
\hline 3 & $\begin{array}{l}8.8 .2016- \\
10.8 .2016\end{array}$ & 38 & 10 & 28 & Sarawak \\
\hline
\end{tabular}

Instrument

To investigate the participants' readiness and acceptance towards cloud community, a set of questionnaires was adapted from previous studies (Rahamat, 2013; Arnone, 1999). The instrument consisted of 5 Likert Scale items which range from scale 1 to 5 which had the values of: $1=$ strongly disagree, $2=$ disagree, $3=$ slightly agree, $4=$ agree, and $5=$ strongly agree. All the Likert Scale items as well as the open-ended questions were focused on the two main constructs: readiness and acceptance. The distribution of the sections in the questionnaire is as presented in the following table.

Table 3: The Sections in the questionnaire.

\begin{tabular}{cllc}
\hline Section & \multicolumn{1}{c}{ Item } & No. of Items \\
\hline A & The brief one paragraph preamble of the & \\
& questionnaire & 5 \\
B $\quad$ Construct 1: Engagement & & 5 \\
& Construct 2: Ease of Use & 5 \\
& Construct 3: Usefulness & 2 \\
C & Open-ended questions & 2 \\
\hline
\end{tabular}


Hazrul, Farish, Rashidah, Abu, G+ Community: Measuring Teacher's Readiness...

To ensure the questionnaire was valid and reliable, the researchers ensured the process of peer checking and internal consistency test were done before the questionnaire was uploaded to the canvas platform. The face and construct validity processes were carried out much earlier before the course started and involved some English language experts in the institution. Based on the input, no changes were made to the items. In terms of ensuring the reliability of the items, SPSS version 18 was used. Analysis of the reliability test found that the values of each constructs were high. According to Hair et. al. (2006), if the value of Alpha Cronbach (a) is $\geq 0.7$, it is categorized as good. The analysis of item reliability for all 15 items in the questionnaire showed that Alpha Cronbach value is 0.934. With these results, the internal consistency of the items can be classified as good. Based on the analysis of the items for each construct, it has been identified that the values shown also indicated high value of reliability of the 3 constructs which ranges from 0.88 to 0.92 . Therefore, the statistical analysis of the construct provides strong indicator that the items are reliable and measure what they are supposed to measure. The following table shows the summary of the reliability of each construct: -

Table 4: Alpha Cronbach Reliability of the Constructs

\begin{tabular}{lccc}
\hline Construct & $\begin{array}{c}\text { No. of } \\
\text { Item }\end{array}$ & $\begin{array}{c}\text { Alpha Cronbach } \\
\text { Value } \\
\text { (a) } \\
\mathrm{n}=81\end{array}$ & Indicator of a \\
\hline Engaging & 5 & 0.884 & good \\
Ease of Use & 5 & 0.916 & good \\
Usefulness & 5 & 0.925 & good \\
\hline
\end{tabular}

\section{Data Collection and Data Analysis}

Data for this study were collected in stages based on the cohorts of the course. Participants were required to give their feedback on the use of Google Community introduced to them. The collection was done using Google Form labelled as "Perceptions towards the Use of Google Apps-CCL2016". The participants were informed to fill in the questionnaire posted in the CCL Canvas. 


\section{EduLite}

Journal of English Education, Literature, and Culture

Volume 2, Number 2, August 2017

This instruction was given on the last day of the course for all the three cohorts. The data gathered from the Google form were then transferred to the Microsoft Excel 2013 format. This was done for data cleaning as well as data analysis procedure. Data cleaning was done manually; the researchers deleted the incomplete data based on the overall findings. Analysis was done using Microsoft Excel format for the questionnaire, Content Analysis (Byrne, 2003) where the coding and count method (for open-ended questions) using Microsoft Office, and using Google Analytics application tool known as Community Meter application for analysing the online document.

\section{Findings}

Analysis of the findings shall be presented in the following section. The descriptive analysis of the questionnaire will be presented in such a way to answer the research questions: 1 . How is the teachers' readiness towards $\mathrm{G}^{+}$ Community affect their actual use of the application?

The analysis of the findings managed to display that the respondents involved in this study have shown certain degree of readiness towards the cloud community. Their responses towards the engagement items as well as the openended questions indicated the readiness.

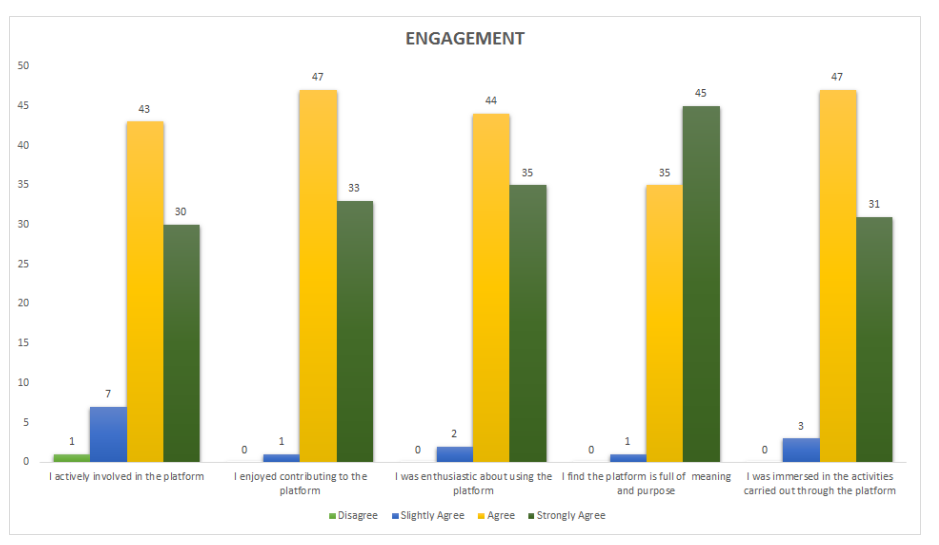

Figure 2: Engagement Construct Analysis 
Hazrul, Farish, Rashidah, Abu, G+ Community: Measuring Teacher's Readiness...

The analysis shows a high number of respondents clicked on the slightly agree, agree and strongly agree buttons. They admitted that they were active in the community where $9 \%(n=7)$ slightly agreed, 53\% agreed $(n=43)$ and $62 \%$ ( $n=50$ strongly agreed). Their readiness is also measured through their positive feelings, which reflected their psychology level. The items analysed showed the participants enjoyed contributing the platform with 58\% agreed and $41 \%$ strongly agreed; they were enthusiastic about using the platform, where 54\% agreed and $43 \%$ strongly agreed; the participants also found the platform useful with $43 \%$ agreed and 56\% strongly agreed to the statement. Besides it is found that, $58 \%$ of them agreed and 38\% strongly agreed that they were immersed with the activities carried out through the platform. To triangulate the findings for this quantitative data, the qualitative data were also retrieved from the analysis of the open-ended questions as well as online document which is based on the postings in the Google+ Community. Figure 3 and 4 display the summary of the analysis towards the online activities done through the community as well as the contributions given.
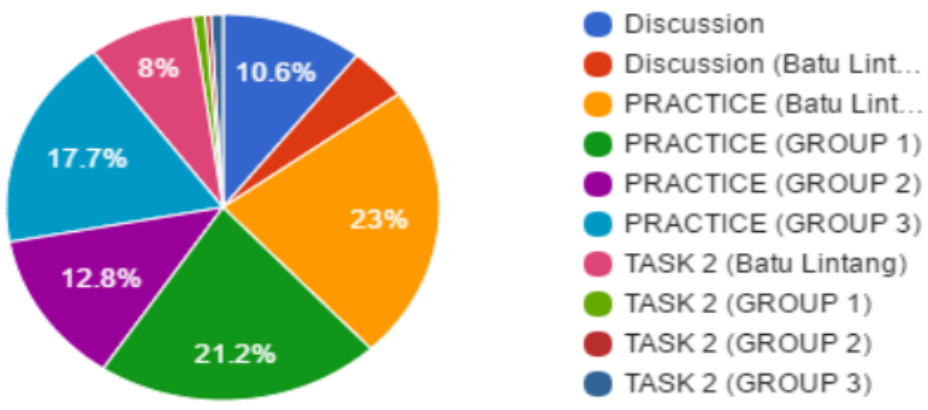

Figure 3: Summary of the Online Activities in the CCL Community

The data gathered from the analysis show that the participants were active particularly during the face-to-face sessions as well as after the course has ended. Figure 3 is the analysis which displays the postings shared in the community during the face-to-face sessions on the 5-7 April 2016, 9-13 May 2016 and 8-10 August 2016. This is shown from the 3 peaks in the diagram. The 


\section{EduLite}

Journal of English Education, Literature, and Culture

contributions of posts after the face-to-face sessions were not that high but, there were some active postings given till 16 September 2016 which is approximately a month after the last cohort ended.

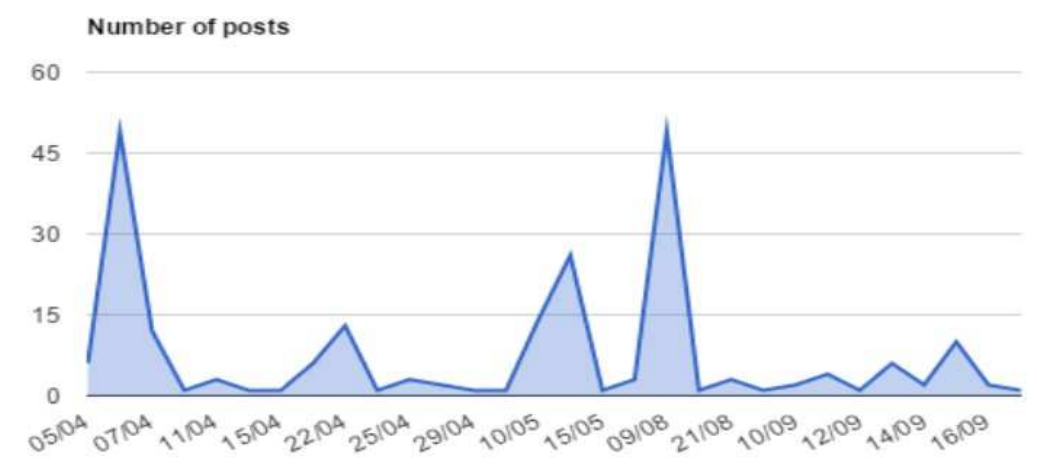

Figure 4: The Contributions in the Community for All the Cohorts

The analysis for second research question of this study: How is the teachers' acceptance towards cloud community affect their actual use of the application? was basically done quantitatively. The analysis made for to get the answer to this research question has led to a definite positive answer. The teachers in this small-scale research have shown positive acceptance towards the cloud community introduced. Quantitative analysis of the two big constructs reflecting acceptance shows majority of the participants responded positively towards all the 10 items. Item 1, which stated "It is useful in work field". The analysis shows that 45 participants agreed (56\%) and another 31 strongly agreed $(38 \%)$ that Google Community is useful in their work field. Analysis of the second and third items for this construct also shows high degree of approval that the tool made it easier for them to accomplish their tasks as well as it also met their work needs. In addition, majority of the participants agreed $43 \%(n=35)$ and strongly agreed 36\% ( $n=29)$ that Google Community saves time. The bar graph below shows the overall findings for the usefulness construct. 
Hazrul, Farish, Rashidah, Abu, G+ Community: Measuring Teacher's Readiness...

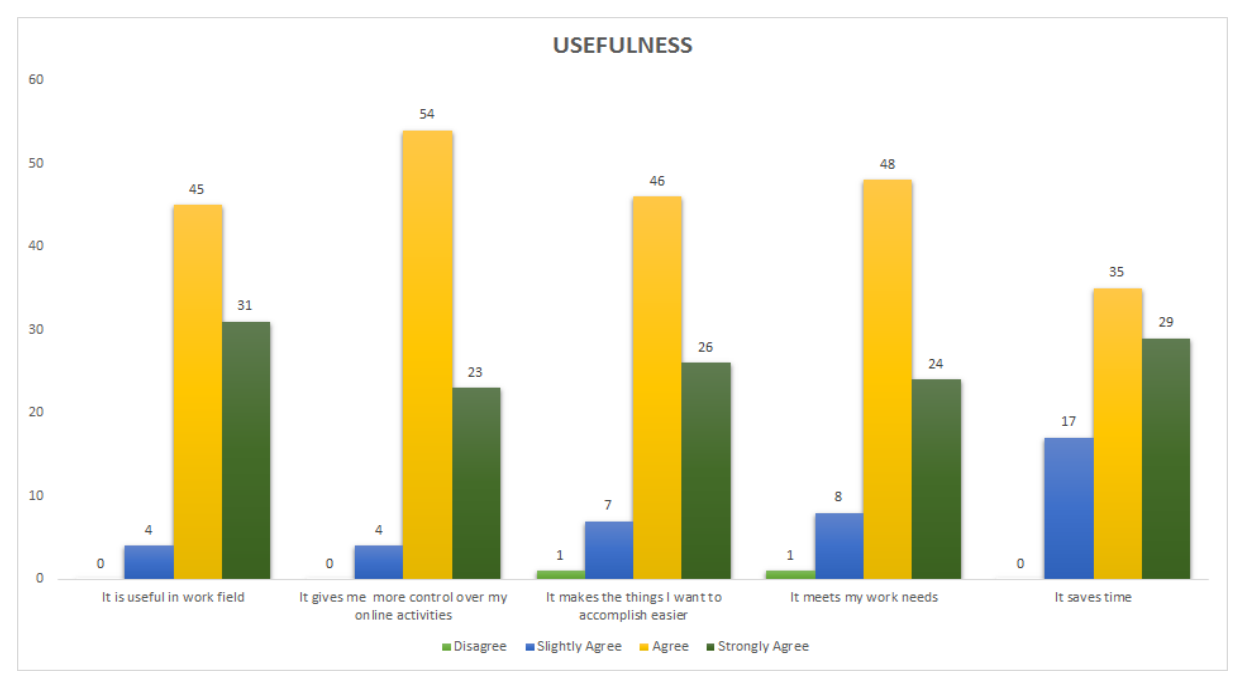

Figure 5: Analysis of the Usefulness

The analysis of the ease of use construct also shows a positive reaction towards the cloud community introduced. The analysis of the 5 items gives strong indication of accepting the use of the community as part of their virtual collaborations as well as interactions. The findings show that $96 \%(n=78)$ of the participants agreed to strongly agreed that the platform is easy to use with the distribution of $20 \%(n-=16)$ slightly agreed, $47 \%(n=38)$ agreed and $30 \%(n=24)$ strongly agreed. Apart from that, they also agreed that the platform is simple to use where, $26 \%(n=21)$ slightly agreed, 47\% $(n=38)$ agreed, 26\% $(n=21)$ strongly agreed and only $1 \%(n=1)$ participant disagreed. As for the statement that the platform requires fewest steps, 4\% $(n=3)$ disagreed, 20\% $(n=16)$ slightly agreed, $54 \%(n=44)$ agreed and $22 \%(n=18)$ strongly agreed. As for the fourth item, "It is flexible", 99\% $(n=80)$ agreed and only $1 \%(n=1)$ disagreed. The analysis of the final item indicated that majority of them agreed that they could use the platform successfully $(3 \%(\mathrm{n}=2)$ disagreed; 22\% $(\mathrm{n}=18)$ slightly agreed; $51 \%(\mathrm{n}=41)$ agreed; $25 \%(n=20)$ strongly agreed). 


\section{EduLite}

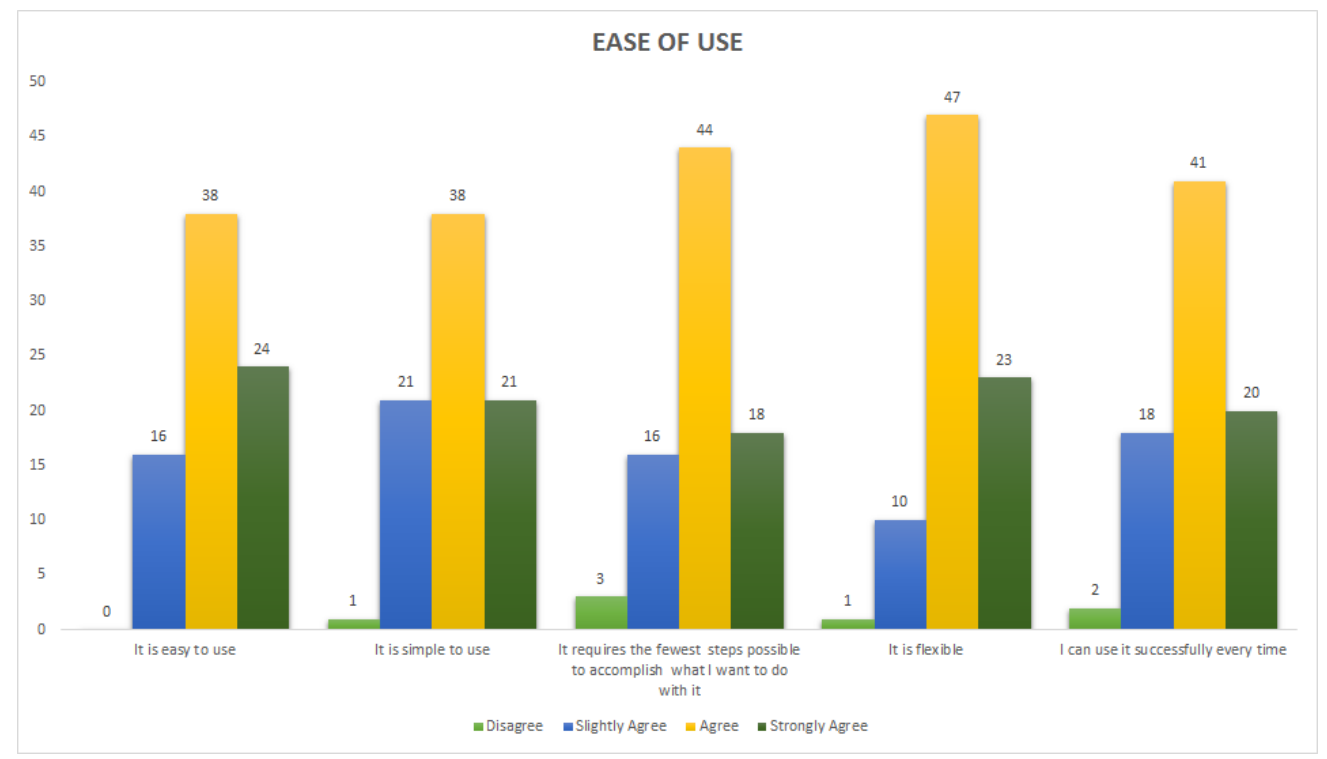

Figure 6: Analysis of the Ease of Use

\section{Discussions}

The objectives of this study are to seek answers to the readiness and acceptance towards cloud community which was created using the Google+ Community platform. The data analysed has given the researchers a few interesting points of discussions. Answers to the questions posed earlier in the paper show a very clear indication that the teachers involved in the study are having a certain degree of readiness towards the cloud community and they are accepting it.

The Teachers' level of Readiness towards G+ Community

In this small-scale research, readiness was measured both through the first 5 items on engagement as well as the online document created from the Google application. Engagement factor was considered as one of the constructs used to explore and analyse the readiness towards using the system or technology. According to Nakamura \& Csíkszentmihályi (2002), a mental state where the individual is focused, motivated and fully immersed in an activity or a task can be categorised as having the optimal concentration where "...the 
Hazrul, Farish, Rashidah, Abu, G+ Community: Measuring Teacher's Readiness...

experience itself is so enjoyable that people will do it even at great cost, for the sheer sake of doing it". The findings presented earlier which show the majority of the participants were immersed with the task can be taken as empirical support for what Nakamura \& Csíkszentmihályi (2002) have stated. This is also a proof that the teachers involved were psychologically ready towards this virtual community and this is in accordance with what Turnbull (2010) categorizes readiness.

The analysis of the online document further strengthens the notion that the teachers are ready. Postings were shared in the community even after the face-to-face sessions have ended. Uploading of materials which was done individually without asking the trainers to explain the process is another proof to support the belief that these groups are ready. Their ability to upload materials and comments on them is another point showing that the teachers are technologically ready. If based on the 9 Levels of Technology Readiness (Banke, 2010), the teachers have fulfilled the requirement to be categorized up to the 6th Level where "... technology demonstrated in a relevant environment".

Ability to share the activities conducted in their own context through the community is evidence to acknowledge their technology readiness level. Another interesting point of discussion of this study, according to technology readiness index given by Parasuraman (2000), these groups of teachers can be classified under the optimism and innovativeness; however, their optimism and innovativeness cannot be endorsed as high, medium or low. It can be assumed that these teachers may have some feelings of discomfort and insecure each time they contribute in the post or try to upload something, but, signs of readiness to use the technology are good indicators to further explore it for their teaching and learning.

\section{Teachers' Acceptance towards Cloud Community}

According to TAM model, the answers to the second question could be gauged through the constructs of perceived usefulness and perceived ease of use 


\section{Edulite}

Journal of English Education, Literature, and Culture

Volume 2, Number 2, August 2017

(Venkatesh \& Davis, 2000; Chuttur, 2009). Findings of the high percentages of responses in the continuum of agreement (from slightly agree to strongly agree) are good indicator that the participants are accepting the platform as their virtual community allowing them to connect and collaborate despite of time and space. It is very interesting and encouraging to see high level of acceptance. The findings are indeed supporting the proposed concept by TAM: when the technology or system is found to be useful and easy to be used, people will accept it. Even though some of these respondents were very senior and some are not that techno-savvy type of people, the step-by-step explanation given to make the process of becoming the members, uploading the materials produced and commenting on others' work through the community is a good step taken. The humanistic touch created during the face-to-face session has been great help as ice-breaker introducing the platform. As human, teachers too need to be given support and feedback on their work. The importance of face-to-face communication is still considered vital. As mentioned by Grossman (2011), there are 6 reasons to highlight the importance of face-to-face communications which are: 1. demonstrate importance, 2. interpret thoughts and feelings, 3. enhance credibility and trust, 4. build relationships, 5. gather feedback and, 6. address sensitive issues.

\section{CONCLUSION}

The rich data gathered from this group of teachers is indeed a good indicator or guide for the teacher trainers to implement a better approach in integrating or introducing the social media or trending technology in the classroom. The importance of knowing the teachers' readiness and acceptance shall help teacher trainers mould the teachers to be up-to-date with the latest use of technology. When the teachers have the knowledge, ready and accept the use of any technology, they must put into practice. This is what has been mentioned by Joosten (2012. p.16),

"To truly reach pedagogical success with an emerging technology, educators should make sure to spend time in the environment, 
Hazrul, Farish, Rashidah, Abu, G+ Community: Measuring Teacher's Readiness...

learn about the culture, understand the norms, and reap the benefits. Participating in social media provides a useful experience in understanding the technology, potentially increasing the effectiveness when implemented in the classroom."

Therefore, by considering the use of Google+ Community as part of the content for teacher training, teacher trainers are helping the teachers to enhance their practices which will eventually affect students' motivation to learn.

\section{REFERENCES:}

Ally, M. (2009). Mobile learning: transforming the delivery of education and training. Canada: AU Press.

Banke, J. (2010). Technology readiness level demystified. Retrieved from https://www.nasa.gov/topics/aeronautics/features/trl_demystified.htm 1. 1.12 .2016 .

Bryne, D. (2003). Interpreting quantitative data. London: SAGE Publications.

Chuttur, M. Y. (2009). Overview of the technology acceptance model: origins, developments and future directions. Sprouts: Working Papers on Information Systems, 9(37). http://sprouts.aisnet.org/9-37.

Grossman, D. 2011. Leading in person: 6 reasons to communicate face-to-face. Leader Communicator Blog, Retrieved from: http://www.yourthoughtpartner.com/blog/bid/44390/Leading-in-Person6-Reasons-to-Communicate-Face-to-Face, 21.12.2016.

Hair, J.F., Black, W.C., Babin, B.J., Anderson, R.E., \& Tatham, R.L. (2006). Multivariate data analysis. New Jersey: Pearson Education Inc.

Hung, D \& Khine, M.S. (Eds). (2006). Engaged learning with emerging technologies. Netherlands: Springer.

Legris, P., Ingham, J., \& Collerette, P. (2003). Why do people use information technology? a critical review of the technology acceptance model. Information \& Management, 40, pg 191-204. Retrieved TKW_091026163722.PDF.

Nakamura \& Csikszentmihályi. (2002). The concept of flow: handbook of positive psychology. New York, NY, US: Oxford University Press. Retrieved from http://eweaver.myweb.usf.edu/2002-Flow.pdf.1.12.2016. 


\section{EduLite}

Journal of English Education, Literature, and Culture

Volume 2, Number 2, August 2017

Parasuraman, A. (2000). Technology readiness index (TRI): a multiple-item scale to measure readiness to embrace new technologies. Journal of Service Research, Vol. 2 (4), 302-307, Sage Publications, Inc. Retrieved from: http://journals.sagepub.com/doi/pdf/10.1177/109467050024001, 20.12.2016.

Rahamat, R. (2013). Development and evaluation of mobile learning package for form 4 literature in English. Unpublished thesis. National University of Malaysia.

Schreurs, J., Ehler, U. \& Moreau, R. (2008). Measuring e-learning readiness. Retrieved:

http://www.uhdspace.uhasselt.be/dspace/bitstream/1942/8740/1/icl08. pdf. 28.12.2010.

Turnbull, J., Lea, D., Parkinson, D., Philips, P., Francis, B., Webb,S., Bull, B., \& Ashby, M. (2010). Oxford advanced learner's dictionary. UK: Oxford University Press.

Venkatesh, V. \& Davies, F.D. (2000). A theoretical extension of the technology acceptance model: four longitudinal field studies. Management Science, 46 (2), 186-204.

Retrieved: http://s3.amazonaws.com/academia.edu.documents/42921312/20002_M S_Venkatesh_Davis_ext_TAM_NO.pdf?AWSAccessKeyId=AKIAJ56TQJRTWS MTNPEA\&Expires $=1482134803 \&$ Signature $=$ PBC1VoZvk9MsWSSLn5unmz5 hR6I\%3D\&response-contentdisposition=inline \%3B\%20filename\%3DA_Theoretical_Extension_of_the_Tec hnolog.pdf. 21.12.2016. 